The diagnosis of diabetes was based on a history of treatment, since glucose concentrations were rarely recorded in the notes. The presence of diabetes thus defined was not associated with increased mortality but was associated with increased risk of amputation. After eight years $20 \%$ of the patients without and $56^{\circ} \%$ of those with diabetes had undergone amputations $(\mathrm{P}<0 \cdot 005)$.

Twenty patients $(13 \%)$ were being treated for hypertension, and their prognosis did not appear to differ from that of patients not receiving treatment; neither did prognosis differ when other arbitrary cut-off points based on the blood-pressure readings recorded in the notes were considered. Smoking habits on first admission were recorded for $117\left(73^{\circ}\right)$ of the 160 patients, $105\left(90^{\circ}\right)$ of whom were smokers or ex-smokers. Smoking habits after referral were rarely recorded in follow-up hospital notes, however, so that the effect on outcome of stopping or reducing smoking could not be determined.

\section{Discussion}

Age, ischaemic heart disease or cerebrovascular disease, and continued smoking were the principal factors associated with an adverse prognosis in patients with IC. Our failure to show the effects of other risk factors on prognosis may have been a consequence of the methods used. Bias, however, is unlikely to have affected the results. The differences observed were highly significant, and probably the factors identified in the two studies are major ones determining patient outcome.

At first our results appear to suggest that there is probably little value in treating hyperlipidaemia or even hypertension, but this may not be so. We considercd several non-fatal adverse events in the life-table analyses, and since the risks of coronary artery disease and stroke-the leading causes of death in patients with IC-are increased with raised serum lipid concentrations and blood pressure, it would be unwise to withhold treatment of these disorders on the basis of these data. A further study is now under way to see whether correcting hyperlipidaemia results in an improved prognosis.

The rate of readmission to hospital of patients with IC was grcater than that of patients admitted with other conditions, and the average duration of each acute admission (18 days) was twice as long as the average duration of admission to general hospitals in the ORLS area for all causes during the period. ${ }^{12}$ Thus IC was associated not only with a significantly reduced life expectancy but also with appreciable morbidity and a considerable drain on health service resources. Smoking was the only correctable risk factor with an appreciable effect on prog-

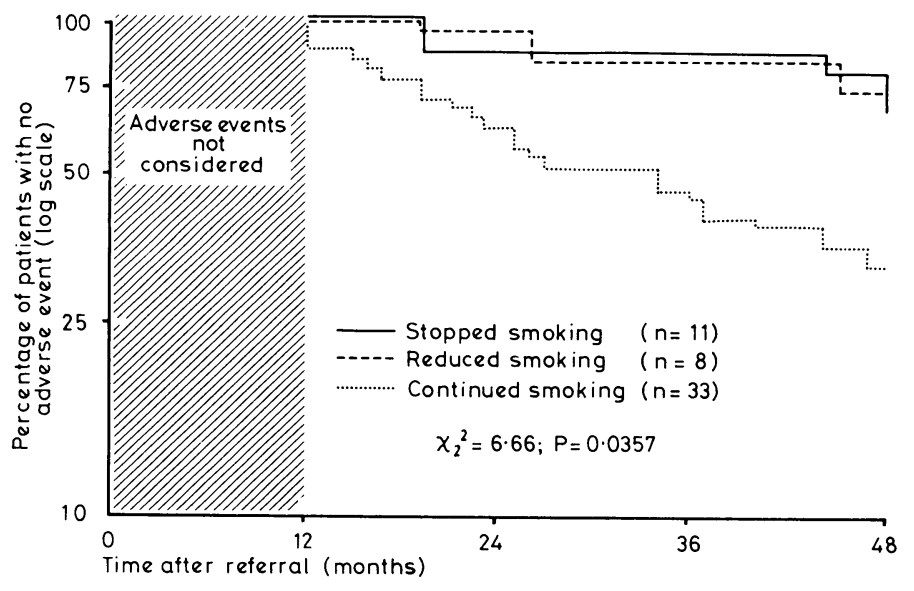

FIG 2-Effect on prognosis of smoking habits after referral.

nosis, and we have found it useful to show patients with IC the life table in fig 2, which illustrates the benefits of stopping smoking. It is extremely important to encourage patients with IC to stop smoking so that the morbidity and mortality associated with the disease may be decreased.

\section{References}

${ }^{1}$ Bloor, K, Annals of the Royal College of Surgeons of England, 1960, 28, 36. 2 Selvaag, O, Acta Medica Scandinavica, 1956, suppl No 319, p 59.

${ }^{3}$ Silbert, S, and Zazeela, H, fournal of the American Medical Association, 1958, 166, 1816.

4 Jeurgens, J L, Barker, N W, and Hines, E A, Circulation, 1960, 21, 188.

${ }^{5}$ Begg, T B, and Richards, R L, Scottish Medical fournal, 1962, 7, 341.

${ }^{6}$ Bergmeyer, $\mathrm{H} \mathrm{U}$, and Bernt, E, in Methods of Enzymatic Analysis, ed H U Bergmeyer. London, Academic Press, 1965.

' Searcy, R L, and Bergquist, C M, Clinica Chimica Acta, 1962, 5, 192.

${ }^{8}$ Eggstein, M, and Kreutz, F H, Klinische Wochenschrift, 1966, 44, 262.

9 DHSS Cancer Epidemiology and Clinical Trials Unit, Survival Analysis Computer Program (SURVC). Oxford, DHSS, 1976.

10 Peto, R, et al, British fournal of Cancer, 1977, 35, 1.

${ }^{11}$ Baldwin, J, Proceedings of the Royal Society of London, 1973, 184, 403.

${ }^{12}$ Fedrick, J, personal communication, 1977.

${ }^{13}$ Central Statistical Office, Annual Abstract of Statistics, Table 12 (1968-70), p 38. London, HMSO, 1971.

(Accepted 17 April 1978)

\title{
Intermittent claudication: prevalence and risk factors
}

\author{
W G HUGHSON, J I MANN, A GARROD
}

British Medical fournal, 1978, 1, 1379-1381

\section{Summary and conclusions}

Risk factors for intermittent claudication (IC) were studied in 54 patients-that is, all patients with IC on the lists of two general practices-and 108 controls. Smoking was the factor most strongly associated with the development of IC, but systolic and diastolic blood pressures and concentrations of triglyceride, urate, and fibrinogen were all significantly higher among the patients with IC than the controls. The presence of more than one factor appeared to be associated with a multiplicative increase in risk. Cholesterol, an important risk factor for ischaemic heart disease, was not associated with an increased risk of IC. IC was present in about $2 \%$ of the men and $1 \%$ of the women, who were aged $45-69$ years.

These findings suggest that IC, a common and disabling manifestation of atherosclerosis, may be largely preventable.

\section{Introduction}

The aetiology of peripheral vascular disease has been less well investigated than other clinical manifestations of atherosclerosis. Data from the Framingham study ${ }^{1}$ suggest that risk factors for peripheral vascular disease may be different from those for ischaemic heart disease and cerebrovascular disease. We studied a group of unselected patients from two Oxfordshire general practices together with controls in an attempt to determine the 
risk factors for intermittent claudication (IC). The method of case identification enabled us to make accurate estimates of the prevalence of IC.

\section{Subjects and methods}

The names and addresses of 1716 men aged 45-69 years and 1535 women aged 50-69 years on the lists of two general practices in Oxfordshire were obtained from the Community Health Project, a computer-based information system. ${ }^{2}$ A questionnaire similar to that described by Rose and Blackburn ${ }^{3}$ for identifying cases of IC was posted to each patient with an explanatory letter. A second questionnaire was sent to each non-responder after one month, and a final approach was made by post to those who had still not responded after a further month. A one-in-five sample of people who had not replied to any of the letters was visited at home or interviewed by telephone to determine whether IC was present

A self-administered version of the Rose and Blackburn questionnaire has been used to study civil servants. ${ }^{4}$ Our responders were more representative of the population and less familiar with filling in forms, and many forms were returned with incomplete or inconsistent responses. We therefore investigated further all whose questionnaires indicated that they experienced leg pain associated with exercise and relieved by rest. A detailed history was taken with use of questionnaires recommended by the World Health Organisation to elicit the symptoms of angina, previous myocardial infarction, and stroke. Smoking habits were noted, the patients' height and weight measured, the legs examined, and peripheral pulses palpated. Ankle systolic blood pressure (ASBP) was recorded at rest and after exercise (climbing 60 steps in 60 seconds) with a Doppler ultrasonic flowmeter. The systolic blood pressure ratio (ASBP:brachial systolic blood pressure), which in normal people is greater than one, was calculated for each leg. ${ }^{5}$ IC was diagnosed in patients who had a history of leg pain associated with exercise and relieved by rest and whose resting ASBP ratio was below 0.75 , with a fall to below 0.6 after exercise. Such patients had diminished or absent leg pulses.

Blood samples were obtained after a 14-hour overnight fast for measurement of glucose,${ }^{6}$ cholesterol, ${ }^{7}$ triglyceride,${ }^{8}$ and fibrinogen ${ }^{9}$ concentrations. A 12-lead electrocardiogram was recorded and classified according to the Minnesota Code $^{3}$ as normal, positive for infarction (codes $1 \cdot 1-1 \cdot 3$ ), or positive for ischaemia (codes $4 \cdot 1-4 \cdot 4$, $5 \cdot 1-5 \cdot 3$, and $7 \cdot 1$ ). For each patient identified as having IC two controls, matched for sex and five-year age group, were selected randomly from the alphabetical listing for each general practice and underwent similar investigations.

Logarithmic transformation of the cholesterol and triglyceride concentrations was carried out before the significance of differences between mean values was assessed with the paired $t$ test. ${ }^{10}$ Relative risks were calculated according to the method described by Pike and Morrow for paired data ${ }^{11}$ since cases and controls had been matched, and standardised relative risks were computed as described by Mantel and Haenzel ${ }^{12}$ to allow for the effects of other risk factors that might have explained some of the increase in risk.

\section{Results}

The overall response rate to the postal questionnaire was $90 \%$. Eighty-six patients who responded indicated that they experienced leg pain associated with exercise and relieved by rest, but the diagnosis of IC was confirmed after interview and examination in 54, 29 of whom had consulted their doctors about their complaint. All but one of the patients with IC had responded to either the first or second postal contact, and no case of IC was found among the sample of non-responders who were telephoned or visited at home. The agestandardised prevalence among the men was $2.2 \%$ and among the women $1 \cdot 2 \%$.

Table I shows the prevalence of ischaemic heart disease and cerebrovascular disease (as defined above) and hypertension, diabetes,

\footnotetext{
Department of Social and Community Medicine, University of Oxford, Oxford OX1 3QN

W G HUGHSON, MD, Rhodes scholar

J I MANN, DM, PHD, lecturer

A GARROD, SRN, research assistant
}

TABLE I-Medical history of patients with intermittent claudication (IC) and controls

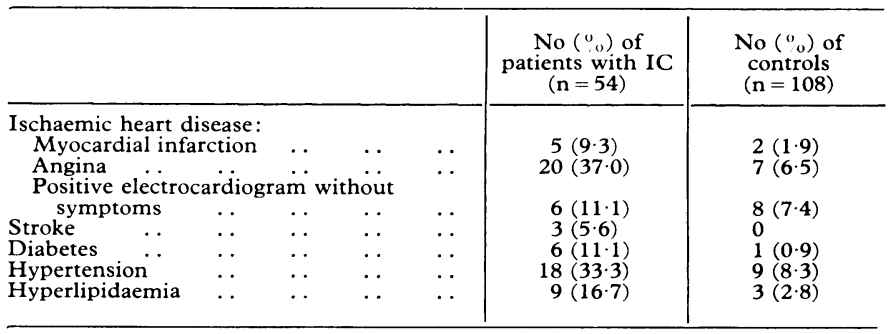

and hyperlipidaemia (defined as drug treatment for any of these) among cases and controls. Table II shows the smoking habits of both groups. The risk of having IC was about nine times greater among those who smoked more than 15 cigarettes daily than among nonsmokers; among those who smoked less than 15 cigarettes daily the relative risk was $6: 1$, and among pipe and cigar smokers $7: 1$. The duration of smoking was significantly longer $(\mathrm{P}<0.001$; MannWhitney $U$ test $^{13}$ ) in the patients with IC (mean 43 years) than in the controls (mean 36.5 years). Numbers were too small to examine men and women separately in detail. Nevertheless, among the men the risk of developing IC was 15 times greater for smokers than for those who had never smoked, whereas among the women smokers the risk was increased only sevenfold.

TABLE II-Smoking habits of patients with intermittent claudication (IC) and controls

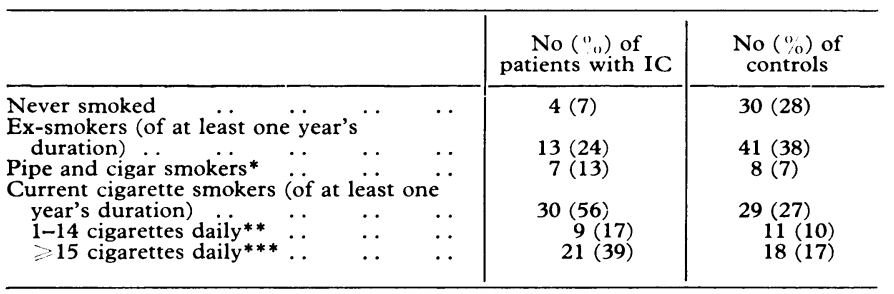

Compared with those who had never smoked: ${ }^{*} \chi_{1}{ }^{2}=5 \cdot 42, P<0 \cdot 025 ; * * \chi_{1}{ }^{2}=5.90$. $\mathrm{P}<0.025 ; * * * \chi_{1}{ }^{2}=14 \cdot 74, \mathrm{P}<0.001$.

TABLE III-Mean ( $\pm S E$ of mean) blood pressure, Quetelet's index, and blood concentrations in patients with intermittent claudication (IC) and controls

\begin{tabular}{|c|c|c|}
\hline Risk factor & Patients with IC & Controls \\
\hline $\begin{array}{l}\text { Systolic blood pressure }(\mathrm{mm} \mathrm{Hg})^{* * * *} \\
\text { Diastolic blood pressure }\left(\mathrm{mm} \mathrm{Hg}^{* * *}\right.\end{array}$ & $\begin{array}{l}164 \pm 4 \\
88 \pm 2 \\
2 \cdot 47 \pm 0 \cdot 05 \\
2 \cdot 32 \pm 0 \cdot 19 \\
6 \cdot 3 \pm 0 \cdot 2 \\
5 \cdot 6 \pm 0 \cdot 3 \\
2 \cdot 64 \pm 0 \cdot 06 \\
363+12\end{array}$ & $\begin{aligned} 147 & \pm 2 \\
83 & \pm 1 \\
2 \cdot 47 & \pm 0 \cdot 05 \\
1 \cdot 92 & \pm 0 \cdot 06 \\
6 \cdot 2 & \pm 0 \cdot 1 \\
5 \cdot 5 & \pm 0 \cdot 2 \\
2 \cdot 48 & \pm 0 \cdot 06 \\
339 & \pm 6\end{aligned}$ \\
\hline
\end{tabular}

Difference between patients with IC and controls: ${ }^{*} \mathrm{P}<0.005 ;{ }^{*} \mathrm{P}<0.001$; ****P $<0.001$

Conversion: SI to traditional units-Serum triglyceride: $1 \mathrm{mmol} / 1 \approx 88.5 \mathrm{mg} / 100$ ml. Serum cholesterol: $1 \mathrm{mmol} / \mathrm{l} \approx 38.6 \mathrm{mg} / 100 \mathrm{ml}$.

TABLE IV-Estimates of relative risk associated with risk factors

\begin{tabular}{|c|c|c|c|}
\hline Risk factor & $\begin{array}{l}\text { Relative risk } \\
\text { of IC }\end{array}$ & $\begin{array}{c}95 \% \text { confidence } \\
\text { limits }\end{array}$ & $\begin{array}{c}\text { Significance } \\
\text { levels }\end{array}$ \\
\hline $\begin{array}{l}\text { Systolic blood pressure } \\
\geqslant 160 \mathrm{~mm} \mathrm{Hg} . . \\
\text { Diastolic blood pressure } \\
\quad 90 \mathrm{~mm} \mathrm{Hg} \\
\text { Serum triglyceride } \\
\text { concentration } \\
\geqslant 2.15 \mathrm{mmol} / 1 . . \\
\text { Serum urate concentration } \\
\geqslant 0.36 \mathrm{mmol} / 1 . \\
\text { Smoking } \geqslant 15 \text { cigarettes } \\
\text { a day } \ldots\end{array}$ & $\begin{array}{l}3 \cdot 4 \\
3 \cdot 2 \\
2 \cdot 0 \\
2 \cdot 6 \\
8 \cdot 8\end{array}$ & $\begin{array}{l}2 \cdot 3-6 \cdot 9 \\
1 \cdot 9-11 \cdot 6 \\
1 \cdot 1-8 \cdot 2 \\
1 \cdot 3-5 \cdot 3 \\
3 \cdot 0-25 \cdot 6\end{array}$ & $\begin{array}{l}\chi_{1}^{2}=11.8, P<0.001 \\
\chi_{1}^{2}=10.4, P<0.005 \\
\chi_{1}^{2}=4.6, P<0.005 \\
\chi_{1}^{2}=6.8, P<0.01 \\
\chi_{1}^{2}=16.3, P<0.001\end{array}$ \\
\hline
\end{tabular}


Table III shows the mean blood pressures, Quetelet's index, and certain blood concentrations. Table IV shows the relative risk estimates associated with certain risk factors. Use of this statistical technique necessitated the choice of arbitrary cut-off points. Standardisation for each of the other factors found to be associated with an increased risk of IC did not significantly influence the individual risk estimates. Table $\mathrm{V}$ shows the numbers of cases and controls with varying numbers of risk factors. The presence of more than one risk factor appeared to be associated with a multiplicative increase in risk.

TABLE v-Proportions of patients with intermittent claudication (IC) and controls with varying numbers of risk factors, and relative risk of IC

\begin{tabular}{c|c|c|c}
\hline $\begin{array}{c}\text { No of } \\
\text { risk factors }\end{array}$ & $\begin{array}{c}\text { No (".,) of } \\
\text { patients with IC }\end{array}$ & $\begin{array}{c}\text { No (".,) of } \\
\text { controls }\end{array}$ & $\begin{array}{c}\text { Relative risk } \\
\text { of IC }+\end{array}$ \\
\hline None & $2(4)$ & $23(21)$ & $1: 1$ \\
One & $12(22)$ & $50(46)$ & $3: 1^{*}$ \\
Two & $19(35)$ & $24(22)$ & $9: 1^{* *}$ \\
Three & $21(39)$ & $11(10)$ & $22: 1^{* * *}$ \\
\hline Total & $54(100)$ & $108(100)$ & \\
\hline
\end{tabular}

†Compared with patients with no risk factors

${ }^{*}{ }^{2}{ }^{2}=0 \cdot 96$, NS. ${ }^{* *} \chi_{1}{ }^{2}=8 \cdot 1, \mathrm{P}<0 \cdot 005 ; 95^{\prime \prime}{ }^{\prime \prime}$ confidence limits $2-42 .{ }^{* * *} \chi_{1}{ }^{2}=17 \cdot 0$, $\mathrm{P}<0.0005 ; 95$ ". confidence limits 5-65.

\section{Discussion}

About $2^{\circ}{ }_{\circ}$ of men aged 45-69 years and $1^{\circ}{ }^{\circ}$ of women aged 50-69 years experienced IC, though in only 29 of the 54 patients with IC were symptoms sufficiently severe to warrant medical consultation. Thus IC is a common cause of morbidity in this age group.

Associations have been confirmed between IC and cigarette smoking and raised blood pressure, ${ }^{1+15}$ well-known risk factors for ischaemic heart disease. Cigarette smoking was associated with a higher relative risk than any of the other factors identified in our study, and only four of the 54 patients with IC had never smoked. No association was found between IC and hypercholesterolaemia, however, which is one of the most important factors predisposing to the development of ischaemic heart disease. Hypertriglyceridaemia, on the other hand, a controversial risk factor for ischaemic heart disease, has been shown to be a risk factor for IC. ${ }^{16} 17$

Raised concentrations of fibrinogen are associated with increased viscosity ${ }^{14}$ and hyperuricaemia may have a similar effect by increasing platelet aggregation. ${ }^{19} 20$ Higher concentrations of both fibrinogen and urate were found in patients with IC than controls in this and other studies. ${ }^{18} 21$ Increased viscosity may cause diminished tissue perfusion and contribute to the symptoms of IC. ${ }^{22}$ It has been suggested that diuretics could account for the hyperuricaemia, ${ }^{23}$ but in our study this finding persisted even when patients receiving diuretics were excluded. Thus while factors influencing viscosity may be concerned in ischaemic heart disease, they are probably particularly important in IC. In our series, diagnosed diabetes occurred in an appreciable number of patients with IC and only one control. Mean fasting glucose concentrations were similar in the two groups, however, being high in both, which probably reflects the high prevalence of "chemical diabetes" in older age groups. ${ }^{24}$

Probably the most important finding was that smoking was the greatest risk factor for IC. This common and disabling manifestation of atherosclerosis may thus be largely preventable, and every effort should be made to persuade people with IC to stop smoking. The observation that risk factors exert a multiplicative effect may be of clinical importance, since eliminating even one factor greatly reduces the relative risk of IC.

We are grateful to Dr J C Hasler, Dr P M R Hemphill, Dr P A Lawrence, Dr H McEwen, Dr D H Richards, Dr R G Seaver, Dr $T$ I Stewart, and Dr A Wager and their patients for agreeing to participate in this study. Dr J Perry, medical director of the Oxford Community Health Project, kindly provided patient listings. Invaluable help was also received from many other members of these practices. Secretarial help was given by Mrs Ann Read, and financial support was received from ICI and the Oxford Regional Health Authority. Professor M P Vessey, Professor Sir Richard Doll, Professor P J Morris, and Mr D J Tibbs provided invaluable advice. We are grateful to Dr Klim McPherson for statistical advice and to Professor Barry Lewis for carrying out the lipid measurements.

\section{References}

${ }^{1}$ Gordon, T, and Kannel, W B, fournal of the American Medical Association, 1972, 221, 661 .

${ }^{2}$ Baldwin, J A, Statistician, 1972, 21, 325.

${ }^{3}$ Rose, G A, and Blackburn, H, Cardiovascular Survey Methods, Monograph Series No 56. Geneva, WHO, 1968.

4 Rose, G A, et al, Lancet, 1977, 1, 105.

${ }^{5}$ Yao, S T, British Fournal of Surgery, 1970, 57, 762.

${ }^{6}$ Bergmeyer, $\mathrm{H} \mathrm{U}$, and Beint, E, in Methods of Enzymatic Analysis, ed H U Bergmeyer. London, Academic Press, 1965.

7 Technicon, Cholesterol method, N24a. New York.

${ }^{8}$ Cramp, D G, and Robertson, G, Analytical Biochemistry, 1968, 25, 246.

9 Ratnoff, O D, and Menzie, C, Fournal of Laboratory and Clinical Medicine, $1951,37,316$.

10 Truswell, A S, and Mann, J I, fournal of Atherosclerosis Research, 1962, 16, 15.

${ }^{11}$ Pike, M C, and Morrow, R H, British fournal of Preventive and Social Medicine, 1970, 24, 42.

${ }^{12}$ Mantel, N, and Haenzel, W, Fournal of the National Cancer Institute, 1959, 22, 719

${ }^{13}$ Siegel, S, Nonparametric Statistics for the Behavioural Sciences. Japan, McGraw-Hill Kogakusha Ltd, 1956.

14 Jeurgens, J L, Barker, N W, and Hines, E A, Circulation, 1960, 21, 188. 15 Gordon, T, and Kannel, W B, Fournal of the American Medical Association, 1972, 221, 661.

${ }^{16}$ Kremer, V G J, et al, Münchener medizinische Wochenschrift, 1973, 115, 662

17 Greenhalgh, R M, et al, Lancet, 1971, 2, 947.

18 Dormandy, J A, et al, British Medical fournal, 1973, 4, 576.

19 Newland, H, Medical Hypotheses, 1975, 1, 152.

20 Winocour, P D, et al, Lancet, 1977, 1, 959.

${ }^{21}$ Lewis, B, et al, British Medical fournal, 1974, 3, 489.

${ }^{22}$ Dintenfass, L, Julian, D G, and Miller, G E, American Heart fournal, 1966, 71, 587.

${ }^{23}$ Coronary Drug Project Research Group, fournal of Chronic Diseases, 1976, 29, 557.

${ }^{24}$ Keen, H, et al, Lancet, 1965, 2, 505.

(Accepted 22 March 1978) 